\title{
Discussion: Flow resistance of wastewater pumping mains
}

\author{
C. Lauchlan, J. Forty and R. May
}

\section{Hansen, Dalhousie University, Halifax, Canada}

If at all possible, civil engineers will avoid the use of sewage lift-stations in the first place. As a design option they have been likened to 'burying your father in a rented suit' because at no future point in time does the obligation of the municipality to operate such stations cease. The electricity bill must be paid and the station must be maintained, in perpetuity. The web page for this Wallingford-based study indicates that in the UK alone, an astonishing $£ 150000000$ is spent annually on lift-station electricity. Part of this annual energy cost is caused by the necessity to overcome the hydraulic resistance of the 'forcemain' (as they are known in North America), an effect that will usually increase over time. This is primarily because of the build-up of organic slime on the inside of the pipe, a build-up that changes both the apparent absolute roughness $(\varepsilon)$ of the inner wall and the inside diameter $(D)$ of the main. In the case of unlined cast iron and ductile iron forcemains, there may also be corrosion effects. It is therefore certainly of interest to find out if a given forcemain has deteriorated to a point where cleaning or replacement of it is warranted, especially if the annual energy consumption is known to be rising.

The pump(s) selected for any given location will have a characteristic curve (Fig. 5(a)). A given location will also have a wet-well and a forcemain that debouches at some higher elevation. System curves (Fig. 5(b)) can be independently developed from knowledge of the expected fluid elevations in the wet-well, the elevation of the outlet and the physical characteristics of the forcemain (especially its diameter, length and roughness). When a pump is put within a wet-well and connected to the forcemain, its expected hydraulic behaviour can be inferred from how the former curve overlaps the latter one (Fig. 5(c)). During ordinary operations the fluid level fluctuates up and down (Fig. 5(b)) frequently during hours of peak household activity and infrequently in the middle of the night. During a 'pump-down' test, the fluid level in the well declines (Fig. 5(f)) and so does the rate of flow. The procedure used to make inferences about the condition of the forcemain is common and in most cases involves measuring the amount of time needed to remove a known volume from the well. When this happens, the velocity in the main will decline somewhat because the static head increases (Fig. 5(b)) causing a migration away from the initial point $a$ and toward the nominal endpoint for the test, $b$ (Fig. 5(c)). If the relative roughness of the main does not change during the test, this migration would correspond to a decline in the Reynolds number and a corresponding increase in the Darcy-Weisbach friction factor (Fig. 5(d)). Data points of $f_{\text {DW }}$ versus Re should fall on curves that lead to reliable inferences about $k_{\mathrm{s}} / D$ (also commonly referred to as $\varepsilon / D$ ), as in Fig. 5(e).

For the tests in which the flow was inferred by evacuating a known volume $j k h_{\mathrm{ww}}$ (the pump-down tests), was the average rate of flow and the average wet-well depth used to infer $k_{\mathrm{s}} / D$, by way of the Colebrook-White equation ${ }^{10}$ If so, how much error was introduced by the fact that both the rate of flow and the fluid level varied during the test, and probably in a non-linear manner? It was not clear from the various footnoted test codes to Table 1 whether the flow for any of the tests was simultaneously measured using both a flowmeter (code M) and estimated by way of volume evacuation of the wet-well. This might indicate how well the volume evacuation method works, especially in cases where the decline in the wet-well was a significant amount compared to total frictional effects, and/or where the characteristic curve of the pump was relatively flat.

It is interesting and possibly significant that the individual tests on specific forcemains behaved in a fairly systematic manner (see selection of tests presented in Figs 6 and 7), unlike the appearance of all of the data for all forcemains, taken as a whole (Fig. 4). When selected data presented in Table 1 are plotted on a Moody-like diagram, it does indicate an increase in Darcy-Weisbach friction factor with decreasing Reynolds number.

However, as can be seen, the curvature of the points for this selection of tests does not follow that associated with the Moody diagram, of which the Colebrook-White equation is an approximation. The authors have explained this as being due to the dependence of the absolute roughness on the velocity of flow. In contrast to Fig. 5(e), the authors have proposed that the apparent absolute roughness decreased with increasing velocity, which implies the kinds of inferences and behaviour on the Moody diagram seen in Fig. 8.

In some cases the $f_{\mathrm{DW}}$ against Re curve is very steep (Cheddington South End), while in others it is quite flat (Clay, Fig. 6). Can the authors suggest possible reasons for this? Mention is made of seasonal variations in the thickness of the interior slime layer. Were all the tests done at the same time of year? The authors found that the type of pipe material was not very helpful in 


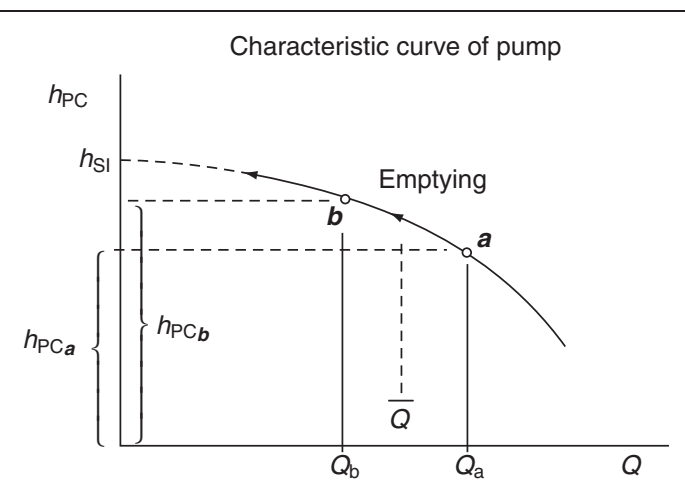

(a)

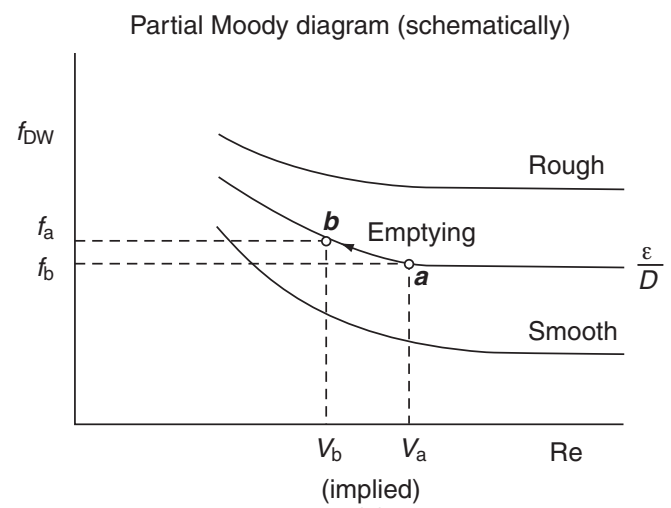

(d)

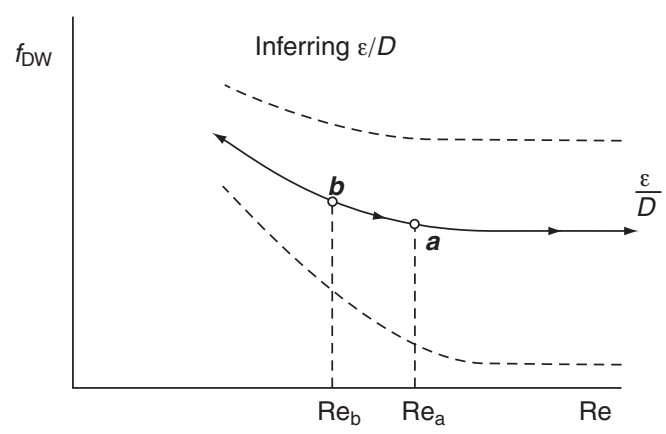

(e)

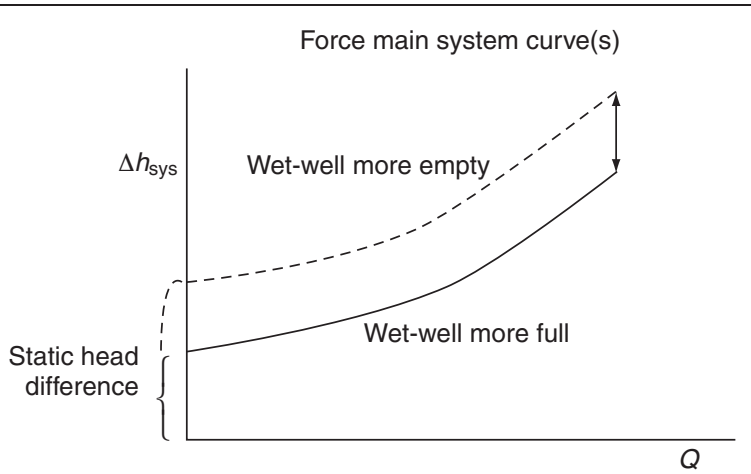

(b)

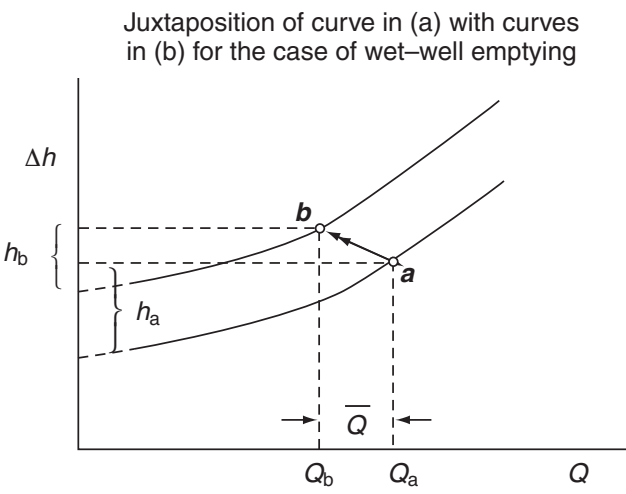

(c)
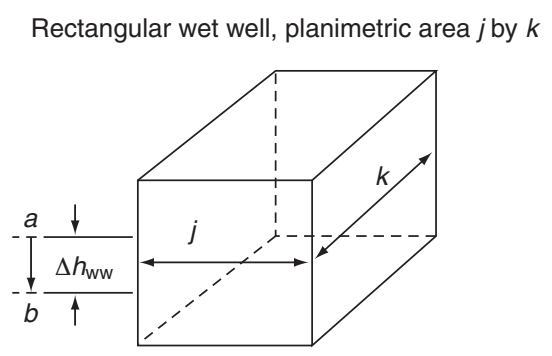

(f)

Fig. 5. Relation between pump characteristic curve, system head curve, wet-well and Moody diagram in the context of making inferences about $\varepsilon D$ (authors' $k_{s} D$ ), the absolute roughness of a given forcemain

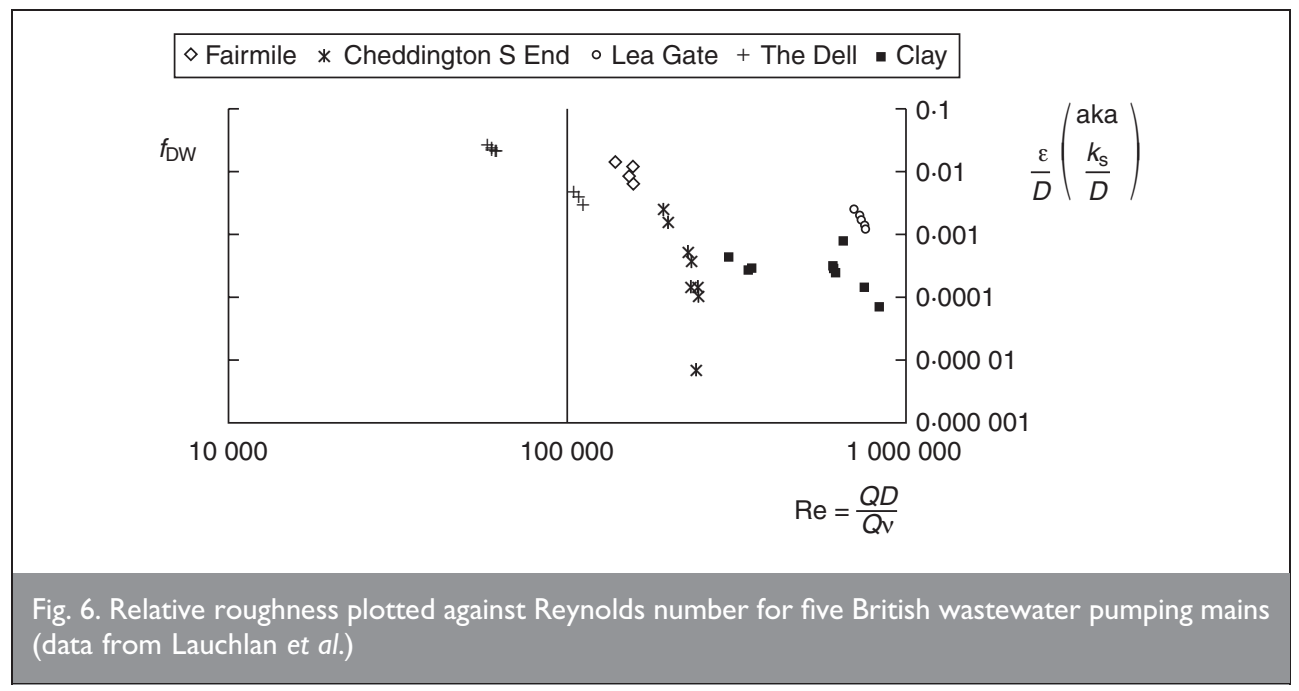

explaining hydraulic resistance (note the two cast iron cases in Figs 6 and 7, 'The Dell' and 'Lea Gate'). However, were some of the pipe materials more consistent in their apparent $k_{\mathrm{s}} / D$ behaviour than other pipe materials? The authors used the Colebrook-White equation ${ }^{10}$ to make their $k_{\mathrm{s}} / D$ inferences; in this same paper relations and guidance regarding the role of the age of the pipe were proposed. Were such approaches found to be of use in separating otherwise similar cases? 


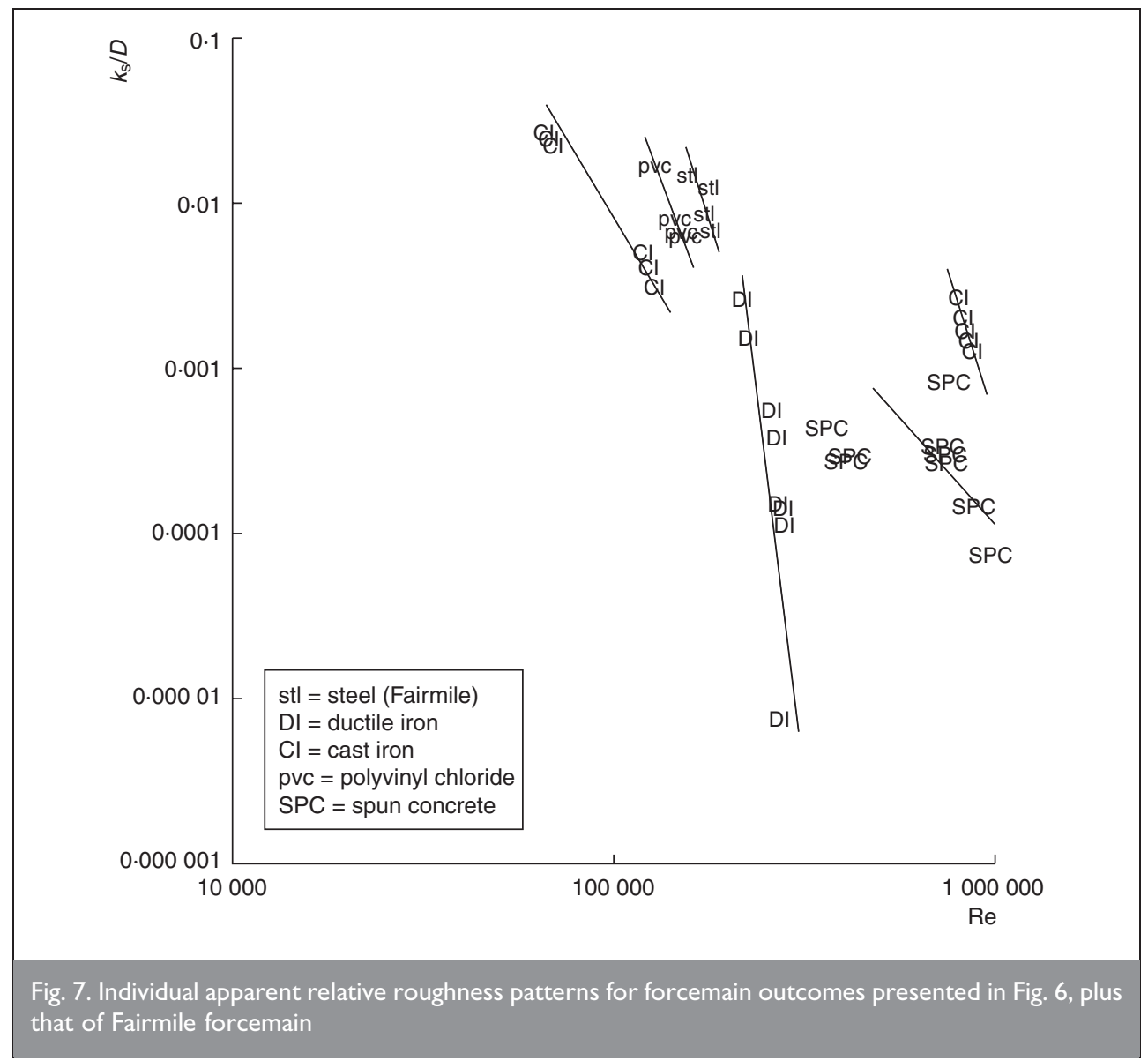

As can be inferred from Fig. 9 (forms of which have appeared in several texts), for any given relative roughness $(R / \varepsilon)$, the Darcy-Weisbach friction factor $f_{\text {DW }}$ actually increases (rather than decreases) for wall Reynolds numbers between about 70 and 200.

The pattern of Nikuradse's data portrayed in Fig. 9 is a plot of re-organised experimental observations; that is, it is more fundamental than the three mathematical expressions that attempt to approximate the three 'regimes' implied by his data. The Colebrook-White equation ('Transition $\mathrm{C}-\mathrm{W}$ ' in the legend) represents a convenient approximation to a transitional behaviour, but one which fails to follow the slope of Nikuradse's data for wall Reynolds numbers between about 70 and 200. With regard to the Colebrook-White equation and the Moody

The Colebrook-White equation conveniently describes the transition between 'smooth' pipe flow and 'rough' pipe flow. The true nature of this transition can be represented using a diagram which pre-dates Lewis Moody's diagram of 1944. Its abscissa is a 'wall Reynolds number'

$$
\operatorname{Re}_{\text {wall }}=\frac{\operatorname{Re} \sqrt{f_{\mathrm{DW}}}}{R / \varepsilon}
$$

where $R$ is the pipe radius, and its ordinate is a generalized resistance function

\begin{tabular}{|l|l|}
\hline 4 & $F_{\text {gen }} \frac{1}{\sqrt{f_{\text {DW }}}}-2 \log _{10}\left(\frac{R}{\varepsilon}\right)$ \\
\hline
\end{tabular}

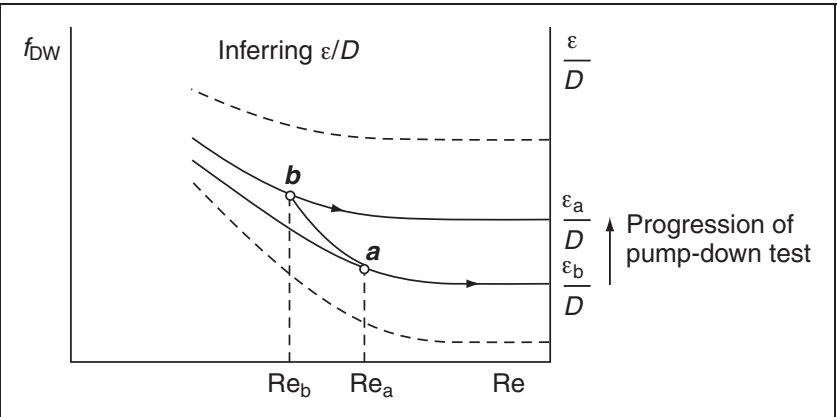

Fig. 8. Shift in apparent relative roughness with increasing Reynolds number (conceptual, on schematic version of Moody diagram) diagram in general, Morris and Wiggert, ${ }^{11}$ (p. 72) have commented that

'... the actual experimental transition function of Nikuradse ... is exactly opposite in character to the Colebrook function, showing (instead) the friction factor as primarily an increasing function of Reynolds number... there are (also) many data indicating that the Colebrook equation is not an adequate description of this relation.'

Notably, Morris and Wiggert ${ }^{11}$ go on to explain that the widespread idea that roughness elements of a given radial height are solely responsible for the nature and intensity of the turbulence-driven losses is wrong, and that in fact

(a) it is only one aspect of conduit roughness that affects turbulence

(b) it is not the most important one.

Another important aspect is known to be the longitudinal spacing of roughness elements. Perhaps forcemains, with their headers and many other appurtenances, generate and transport turbulent vortices by complex mechanisms, the size and propagation of which may indeed be longitudinal in their effects. Although the minor-loss $k$ value of a medium-radius elbow is often simply taken to be $0 \cdot 75$, Pigott ${ }^{12}$ has presented a more general expression showing its dependence on $f_{\text {DW }}$. Forcemains may also have different effective diameters (slime thicknesses) along their length, probably depending on such things as proximity to appurtenances and to the surface of the ground (i.e. temperature effects). Mention is made of air pockets in section 4.4. Such variably sized constrictions would act like localized 'roughness' elements that may well be longitudinal in their turbulence-generating effects. 


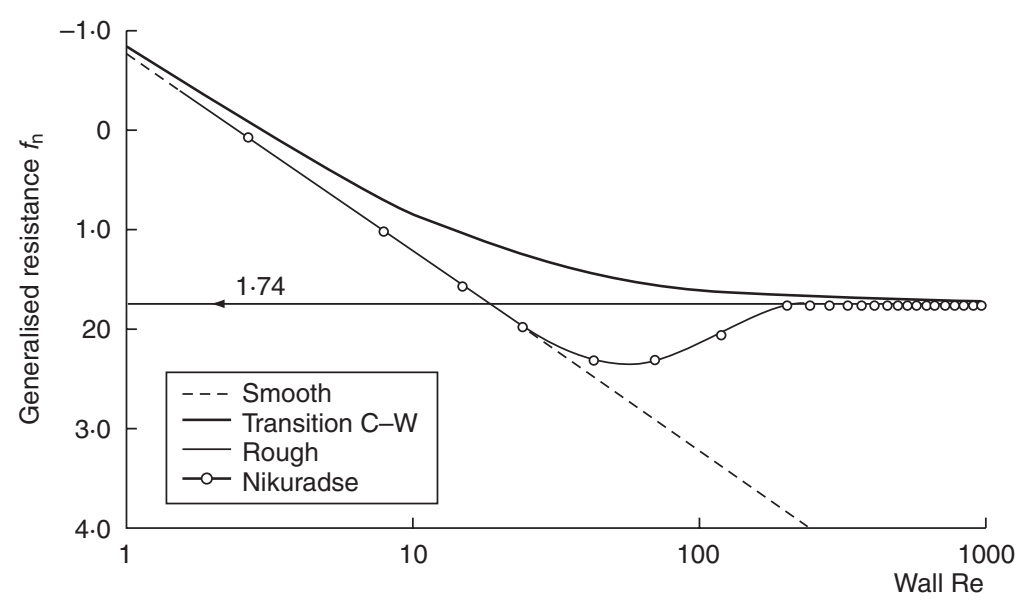

The idea of a decrease in internal roughness with flow is central to the authors' interpretation of their data. A well-known example that represents a visible decrease in roughness height with an increase in velocity is the bending over of vegetation in swales. Can the authors suggest whether the organic slime layer is doing this, perhaps because it is filamentatious in character, or whether hydraulic shear may be compressing a more gelatinous type of coating? The presence of a gelatinous layer would perhaps be better represented as a reduction in

(In Canada, forcemains are normally required to have air-relief chambers at topographic high points. However, because such air-relief valves become fouled with grease too frequently when operating on wastewater pressure conduits, vertical bends are avoided at the design stage, if at all possible. Such valves require chambers in order for said maintenance to be performed, both of which represent a cost.) Izquierdo et al. ${ }^{13}$ have described the hydraulic conditions that can drive air entrapped in pressure conduits downstream. Air pockets trapped at high points should be larger in the morning and smaller at the day's end, so that the time of day of the test may have affected the authors' results. Which, if any, of the forcemains tested passed over topographic high points?

The authors state that the internal diameters of the forcemains tested were not measured. As can be seen from the system curves in Fig. 10, a mere 10\% decrease in diameter has more effect on hydraulic resistance than a doubling of absolute roughness. Can the authors speculate about the possible confounding effects of a reduction in the apparent diameter of the forcemains considered in their particular study? The apparent relative roughness for the forcemain at Cheddington South End was found to vary by 360 times, over two orders of magnitude (Fig. 6)! It seems difficult to believe that this was due solely to the compression of slime layers. apparent pipe diameter, and given Fig. 10 it may be more consistent with the overall findings. With regard to the issue of pipe diameter, it seems hard to justify reporting same to $0 \cdot 1 \mathrm{~mm}$ when these were not measured (statement in first complete paragraph on p. 84), yet to infer that $\varepsilon / D$ was highly flow dependent for a given forcemain.

R. J. S. Pigott (cited by Daugherty and Franzini ${ }^{14}$ ) has noted that the partially developed turbulence zone of the Moody diagram may be defined by

5 Laminar $(2500$ nominal $)<\operatorname{Re}<\frac{3500}{\varepsilon / D}$

By the present writer's count, in 31 of the cases in the authors' Table 1, the Re exceeded the upper limit of this zone, and the tests were therefore in the fully developed turbulence zone (where $f_{\mathrm{DW}}$ is independent of Re and depends only on $\varepsilon / D$ ). Might not a division of the data according to flow regime have improved the interpretations?

Finally, the authors have presented a power function fit that relates absolute roughness and velocity. There is considerable scatter in the relationship presented [Fig. 4 and equation (2)]. In order to obtain a power function, it is common practice to perform the regression analysis on the logarithms of the data. However, the resulting power functions will tend to underestimate the dependent variable; in this case, the socalled equivalent sand grain roughness $k_{\mathrm{s}}$ (denoted $\varepsilon$ herein). The existence of this underestimation has been discussed in general terms by statisticians such as Finney ${ }^{15}$ and Duan; ${ }^{16}$ applications related to water resources engineering have been presented by Ferguson, ${ }^{17}$ Koch and Smillie ${ }^{18}$ and Walling. ${ }^{19}$ 
The theory behind it and the justifications for it will therefore not be restated here. Laughlin et al. have provided us with an example of the very oversight described by these various authors. They present

\section{2}

$$
k_{\mathrm{s}}=\alpha V^{\beta}
$$

which, according to this writer's analysis of the data printed in the authors' Table 1 , had a standard error (SE) of about 1.0 (in $\log _{10}$ units), an 'average' $\alpha$ of $0 \cdot 446$, and a $\beta$ of $-2 \cdot 34$. Equation (2) was probably obtained by re-arranging

\begin{tabular}{|l|l|}
\hline 6 & $\log \left(k_{\mathrm{s}}\right)=\log (\alpha)+\beta \log (V)$ \\
\hline
\end{tabular}

The standard error may be computed from

\begin{tabular}{|l|l|}
\hline 7 & $\mathrm{SE}=\left[\frac{1}{n-k-1} \sum_{i=1}^{n}\left(Y_{i}-\hat{Y}_{i}\right)^{2}\right]^{1 / 2}$ \\
\hline
\end{tabular}

where (if $Y$ is denoted to be $\log$ of $k_{\mathrm{s}}$ ), $n$ is the number of data points, $k$ is the number of independent variables ( 1 in this case), $Y_{i}$ is the value of 'observed' data point $i$ (in this case, the log of the $k_{\mathrm{s}}$ values), and $\hat{Y}_{i}$ is the value of computed data point $i$ [in this case, $\log \left(k_{\mathrm{s}}\right)$ from equation (6)].

Using a "naïve estimate' 15 of the bias, a correction factor for the authors' equation (2) may be computed using

$$
8 \quad C_{\mathrm{F}}=\exp \left[2 \cdot 65 \cdot \mathrm{SE}^{2}\right]
$$

where SE is a standard error, found using equation (7) [noting how the terms in equation (4) are defined], and $C_{\mathrm{F}}$ is the correction factor for the bias caused by the non-linearity of the $\log _{10}$ transformation $2 \cdot 65=\ln (10)^{2} / 2$.

From the authors' data in Table $1, C_{\mathrm{F}}=14 \cdot 1$. This means that the roughness values predicted using their equation (2) will be much smaller than they ought to be. If the assumptions herein are correct thus far, the result of a rudimentary attempt at correcting the bias present in equation (2) results in

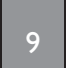

$$
k_{\mathrm{s}}=14 \cdot 1(0 \cdot 446) V^{-2 \cdot 34}=6 \cdot 3 V^{-2 \cdot 34}
$$

Duan's ${ }^{16}$ correction for the bias is better in that it is more flexible. Duan refers to it as a 'smearing estimate' of the bias, one for which no assumptions are required regarding the distribution of the residuals in log space. For $\log _{10}$ transformed data, it may be computed as

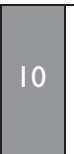

$$
C_{\mathrm{D}}=\frac{1}{n} \sum_{i=1}^{n} 10^{\varepsilon_{i}}
$$

where $\varepsilon_{i}$ is the magnitude of residual $i$ in $\log$ space.

That is, Duan's correction factor is simply the mean back-transformed residual. Again, using the data provided in
Table 1 , it was estimated that $C_{\mathrm{D}}$ is about $5 \cdot 0$, leading to

$$
k_{\mathrm{s}}=5 \cdot 0(0 \cdot 446) V^{-2 \cdot 34}=2 \cdot 21 V^{-2 \cdot 34}
$$

If it is believed that the power function presented by Laughlin et al. is useful from an engineering point of view, then at least one of the above corrections should theoretically be applied to it. However, this writer believes that application of equation (2) to generate system curves for the very forcemains tested would result in curves that would bear little resemblance to most of the original forcemain system curves, for reasons that have nothing to do with the statistical bias associated with the non-linear transformation of the raw data.

\section{Authors' reply}

The hydraulic roughness values presented in the paper are composite values that take into account the effect of the surface texture of the pipe and any loss in flow area due to the possible presence of slime layers or small air pockets. The test data were analysed using the Colebrook-White equation; this is widely used in design practice in UK and Europe, and has the advantage of being applicable to both the fully-rough turbulent and transitional flow regimes that occurred in the tests. Dr Hansen appears to suggest that use of the Colebrook-White equation is inappropriate because it does not match the type of transition between smoothturbulent and rough-turbulent flow found by Nikuradse (see Fig. 9). Nikuradse's pipes were artificially roughened by gluing sand particles to the walls of smooth pipes and so were not representative of the types of roughness that are found in commercially available pipes. Many experimental studies on manufactured pipes have shown smooth transitions similar to those given by the Colebrook-White equation, which is one of the principal reasons for its wide adoption. A detailed review of the experimental basis for the equation can be found in Ackers. ${ }^{20}$

For each test the average flow rate was used to determine the hydraulic resistance. It was found in the majority of cases that the flow rate did not vary significantly with time during a test. However, the pressure measurements did show variations over a test cycle, particularly as the pumps started up and shut down; for calculation of the hydraulic roughness, the average value of pressure head was therefore used. Sensitivity tests on the calculations were carried out using values of instantaneous flow rate and maximum and minimum recorded pressures. The variances in $k_{\mathrm{s}}$ about the average values when using the maximum or minimum recorded pressure heads were within the upper and lower bounds given by the prediction equation. For more details of the sensitivity tests, see the project report. ${ }^{2}$

Flow rates were not measured simultaneously using a flowmeter and a pumping well test. Initially, direct measurement using a strap-on ultrasonic flowmeter was considered. However, inspections of the various sites showed that in almost all cases there was not enough exposed pipe within the dry well to allow fitting of a strap-on meter. For the tests on the larger United Utilities mains, permanently installed electromagnetic flowmeters were used. At these sites no access to the wet-well was possible so simultaneous pumping well tests could not be conducted.

As part of the study the effects of flow velocity, pipe diameter, pipe material, pipe sliming and shear stress were analysed in order 


\begin{tabular}{|lccc|}
\hline \multicolumn{1}{|c}{ Material } & $\begin{array}{c}\text { Number of } \\
\text { pipelines } \\
\text { tested }\end{array}$ & $\begin{array}{c}\text { Average } \\
\left(\frac{\text { measured } k_{\mathrm{s}}}{\text { predicted } k_{\mathrm{s}}}\right)\end{array}$ & $\begin{array}{c}\text { Standard } \\
\text { deviation } \\
\text { ratio }\end{array}$ \\
\hline Steel & 2 & 1.54 & 2.95 \\
Asbestos cement & 2 & 0.44 & 1.75 \\
Ductile/spun iron & 5 & 0.59 & 5.56 \\
Cement mortar & 1 & 2.65 & 1.21 \\
lining in ductile iron & & & \\
Cast iron & 6 & 2.09 & 3.14 \\
UPVC & 6 & 0.49 & 5.96 \\
Polyethylene & 2 & 0.88 & 1.97 \\
Spun concrete & 1 & 0.77 & 2.51 \\
All data & 26 & 1.00 & 4.10 \\
& & &
\end{tabular}

Table 3. Average roughnesses of pipe materials relative to values from prediction equation

to identify any relationships which could lead to an improved method for estimating hydraulic resistance.

(a) Previous studies had shown that flow velocity was a dominant factor and this was found in the present study.

(b) The test results showed that there were differences in $k_{\mathrm{s}}$ values for different diameters of pipe but no clear overall trend was seen. Owing to the variability in the data it was decided not to differentiate between the different pipe diameters.

(c) In terms of pipe material, it was found that pipes with lower values of $k_{\mathrm{s}}$ when clean also tended to have lower values of roughness when used in wastewater pumping mains, although the differences were less clear-cut. The actual variations between the materials were relatively small when compared with the standard deviations of the data (see Table 3) and therefore it was decided not to differentiate between pipe materials. Table 3 shows that the proposed prediction equation tends to underestimate the roughness of pipe materials such as steel and cast iron and to overestimate the roughness of materials such as plastic and ductile/spun iron. Unfortunately the limited data set did not allow further development of a reliable factor to account for the effect of pipe material.

(d) An analysis was performed to investigate the relationship between the shear stress exerted by the flow on the walls of the pipe and the hydraulic roughness of the pipe. It was expected that there might be a relationship between the parameters whereby the higher the value of shear stress was, the smaller the hydraulic roughness would be. No correlation was found so it was concluded that shear stress was not a useful predictor of the hydraulic roughness.

The build-up of slime in a pipe can be expected to have a significant effect on the hydraulic roughness by roughening the walls of the pipe and/or by reducing the cross-sectional area of the flow. Unfortunately, it was not possible to observe the slime layer directly. However, the results of some of the tests indicated that the slime might have had a dynamic behaviour that was related to the flow conditions in the pipe. Increasing the pumping rate in a main during a series of tests tended to produce lower values of roughness. However, this was not necessarily a permanent change because, when in some of the tests the flow rate was lowered, the roughness was found to increase. This suggests that the slime was not stripped away by the flow but was flattened or smoothed by the higher shear stresses acting on it. When the flow rate was reduced, the slime appeared to revert to a rougher condition characteristic of the lower flow velocity.

It was mentioned in the paper that the slime characteristics may vary along the length of the pipe and that other factors may affect the development and growth of the slime layers (such as antecedent rainfall conditions, temperature, presence of sediment, type of wastewater and use of dosing chemicals for odour control). These factors could not be quantified in the study. As tests were conducted all year round, as sites became available, any seasonal effects could not be identified separately.

The data from the tests did not enable the effect of the age of the pipe to be quantified. The proposed roughness values provided in Table 2 are presented in terms of the lower, average and upper likely values of roughness for a range of flow conditions.

Air pockets and their transport through a pipe system may have an impact on the measured hydraulic roughness. The pipelines generally transported flows from topographical low points to treatment works. The situation where a pipe discharges into a gravity main was avoided where possible. Some pipelines had an undulating profile so air pockets may have formed at high points. None of the pipelines tested had operational air relief valves.

It was not possible to measure internal pipe diameters in situ, but much effort was made to estimate the most appropriate value for each of the pumping mains tested. Any error in the value of pipe diameter would have had an effect on the roughness value estimated for a test. However, it is considered that the error bands given with the prediction equation provide a suitable allowance for this element of uncertainty.

Dr Hansen presents an interesting method for correcting what is thought to be an apparent bias in the roughness data. Table 4 presents values obtained using the prediction equation and the corrected equations proposed by Dr Hansen.

(a) The correction based on Finney ${ }^{15}$ results in significantly larger hydraulic roughness values for all flow velocities, while Duan's ${ }^{16}$ correction gives roughness estimates that fall between the average and the upper band of the test data. Since the upper and lower bands represent 95\% confidence limits for the data set, it can be seen that the suggested modifications to the prediction equation do not

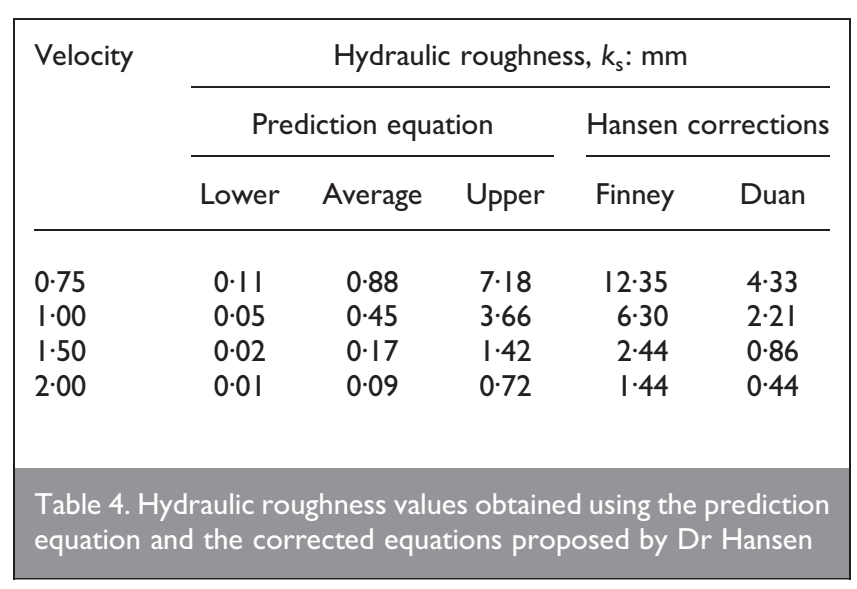


provide a good description of the results that were obtained.

(b) The alternative prediction equations suggested by $\mathrm{Dr}$ Hansen are intended to correct for a bias that occurs when the logarithms of data values are used in standard linear regression. This bias can become a significant factor when data values span several orders of magnitude. However, it needs to be remembered that in the present case the required output is an accurate estimate of the frictional resistance of the pumping main. The value of $k_{\mathrm{s}}$ is only a numerical value that is used 'en route' to calculating the head loss gradient. The Colebrook-White equation shows that in rough turbulent flow the head loss gradient depends on the logarithm of $k_{\mathrm{s}}$ and not directly on $k_{\mathrm{s}}$. Thus the use of the standard linear regression technique is considered to be appropriate in the present case and to provide better estimates of the performance of wastewater pumping mains than the modified equations proposed by Dr Hansen.

\section{REFERENCES}

10. CoLEBRooK C. F. Turbulent flow in pipes with particular reference to the transition region between the smooth and rough pipe laws. Proceedings of the Institution of Civil Engineers, 1939, 11, 133-156.

11. Morris H. M. and Wiggert J. M. Applied Hydraulics in Engineering, 2nd edn. Ronald Press, New York, 1972.
12. Pigott R. J. S. Pressure losses in tubing, pipe, and fittings. Transactions of the American Society of Mechanical Engineers, 1950, 72(July), 679-688.

13. Izquierdo J., Fuertes V. S., Cabrera E., Iglesias P. L. and GARCIA-SERRA J. Pipeline start-up with entrapped air. IAHR Journal of Hydraulic Research, 1999, 37, No. 5, 579-590.

14. Daugherty R. L. and Franzini J. B. Fluid Mechanics with Engineering Applications, 7th edn. McGraw-Hill, New York, 1977.

15. FInNEY D. J. On the distribution of a variable whose logarithm is normally distributed. Journal of the Royal Statistical Society of London, 1941, 7(B), 155-161.

16. DuAN N. Smearing estimate: a nonparametric retransformation method. Journal of the American Statistical Association, 1983, 78, No. 383, 605-610.

17. FERGUSON R. I. River loads underestimated by rating curves. Water Resources Research, 1986, 22, No. 1, 74-76.

18. Косн R. W. and Smillie G. M. Bias in hydrologic prediction using log-transformed regression models. AWRA Water Resources Bulletin, 1986, 22, No. 5, 717-723.

19. Walling D. E. Assessing the accuracy of suspended sediment rating curves for a small basin. Water Resources Research, 1977, 13, No. 3, 513-538.

20. ACKers P. Resistance of Fluids Flowing in Channels and Pipes. Department of Scientific and Industrial Research, Hydraulics Research Station, Wallingford, 1958, Hydraulics Research Paper No. 1.

\section{What do you think?}

To comment on this paper, please email up to 500 words to the editor at journals@ice.org.uk

Proceedings journals rely entirely on contributions sent in by civil engineers and related professionals, academics and students. Papers should be 2000-5000 words long, with adequate illustrations and references. Please visit www.thomastelford.com/journals for author guidelines and further details. 